Review

\title{
Interaction of Natural Organic Matter with Layered Minerals: Recent Developments in Computational Methods at the Nanoscale
}

\section{Jeffery A. Greathouse ${ }^{1, *}$, Karen L. Johnson ${ }^{2}$ and H. Christopher Greenwell ${ }^{3}$}

1 Geochemistry Department, Sandia National Laboratories, P.O. Box 0754, Albuquerque, NM 87185-0754, USA

2 School of Engineering and Computing Sciences, Durham University, South Road, Durham DH1 3LE, UK; E-Mail: karen.johnson@durham.ac.uk

3 Department of Earth Sciences, Durham University, South Road, Durham DH1 3LE, UK; E-Mail: chris.greenwell@durham.ac.uk

* Author to whom correspondence should be addressed; E-Mail: jagreat@sandia.gov; Tel.: +1-505-284-4895; Fax: +1-505-844-7354.

Received: 5 March 2014; in revised form: 3 May 2014 / Accepted: 14 May 2014 /

Published: 6 June 2014

\begin{abstract}
The role of mineral surfaces in the adsorption, transport, formation, and degradation of natural organic matter $(\mathrm{NOM})$ in the biosphere remains an active research area owing to the difficulties in identifying proper working models of both NOM and mineral phases present in the environment. The variety of aqueous chemistries encountered in the subsurface (e.g., oxic vs. anoxic, variable $\mathrm{pH}$ ) further complicate this field of study. Recently, the advent of nanoscale probes such as X-ray adsorption spectroscopy and surface vibrational spectroscopy applied to study such complicated interfacial systems have enabled new insight into NOM-mineral interfaces. Additionally, due to increasing capabilities in computational chemistry, it is now possible to simulate molecular processes of NOM at multiple scales, from quantum methods for electron transfer to classical methods for folding and adsorption of macroparticles. In this review, we present recent developments in interfacial properties of NOM adsorbed on mineral surfaces from a computational point of view that is informed by recent experiments.
\end{abstract}

Keywords: mineral; surface; layered mineral; manganese oxides; manganese; molecular modeling; density functional theory; molecular dynamics; simulation; natural organic matter; humic acid; fulvic acid 


\section{Introduction to Natural Organic Matter-Mineral Systems}

Natural, non-living, organic matter, often referred to as natural organic matter (NOM), plays a critical role in many biogeochemical processes, many of which have been broadly reviewed by Senesi et al. [1]. NOM is presently a relevant topic in terms of its role in global carbon budgets and cycling [2], organic matter preservation and conversion in petroleum systems [3], the stabilization and degradation of other contaminants [4] and within industrial contexts of water treatment [5], and particularly fouling in desalination plants [6].

Structurally, NOM is extremely complex with a three-dimensional macromolecular structure and consisting of a diverse group of organic molecules [7]. At the moment, there is no consensus on the primary binding mechanism holding the aggregated molecules that comprise NOM in place. However, the nature of the major functional groups present in NOM has been well characterized, with groups such as carboxyl, hydroxyl, phenolic, alcohol, carbonyl and methoxy, all present. Within these, carboxyl and phenolic groups are considered the most important functional groups responsible for the adsorption of NOM onto metal oxides [8]. Most NOM in sediments is present as molecularly-uncharacterized carbon (MUC) [9] and occurs in soil humus (globally estimated to be $\sim 1.6 \times 10^{18} \mathrm{~g}$ of carbon (gC)) and recently deposited marine deposits $\left(1.0 \times 10^{18} \mathrm{gC}\right)$. MUC is so-called because it is not easily characterized as recognizable distinct organic molecules such as amino acids, sugars, lipids or lignin. Organic matter stabilized at mineral surfaces within sediments is, generally, less available to microorganisms and therefore plays a role in the overall removal of fixed $\mathrm{CO}_{2}$ from the atmosphere [10].

The role of minerals in the stabilization of NOM in soils has been reviewed by von Lützow et al. [11], and two key pathways for the role of minerals in NOM preservation are proposed: (i) spatial inaccessibility against decomposer organisms due to, for example, occlusion or intercalation within the structure of layered minerals; and (ii) stabilization through interaction with mineral surfaces. More generally, Weber et al. [12] proposed a model of two types of natural organic matter within soils and sediments, "soft carbon" (amorphous or hydrolysable carbon) which is extractable at low temperatures with acids and/or bases and "hard carbon" (condensed or non-hydrolysable carbon) which is not extractable with acids and/or bases but is released at high temperatures. This "hard" stable carbon pool is thought to be composed of "humin" or "protokerogen" bound to mineral surfaces [13]. There is no current consensus on how organic matter becomes partitioned into hard and soft pools. Theories include geopolymerization, selective preservation of refractory molecules and physical protection of organic matter by mineral occlusion [2,10]. Geopolymerization (humification) is a general term to describe the oxidative polymerization of low molecular weight monomers and is thought to be catalyzed by mineral surfaces [14].

Though the interactions of NOM with mineral surfaces is fundamentally important within many natural processes [15], hitherto research in the area has seen a disconnect between the macro-scale and nano-scale. In other areas of research where analogous materials are present, for example within crude oil formation [16,17], clay-polymer nanocomposite materials [18] and heterogeneous catalysis [19,20], there have been concerted efforts to understand macroscopic phenomena in terms of nano-scale surface interactions between the organic molecules and the mineral surface. These have been undertaken using nano-scale surface chemistry methods and, increasingly, computer simulation. The latter has become an essential adjunct to understanding complex chemical structures and reactivity at 
surfaces, often beyond the resolution of analytical methods, or simply not possible to analyze without drastically perturbing the system of interest. NOM presents a severe challenge to analysis using computer simulation and closely coupled experiments owing to its complexity, high molecular weight and diversity, which leads to difficulty in both experimental characterization of NOM and building molecular models of NOM, though present day computational chemistry resources have now matured sufficiently to begin to make such problems tractable [21].

In this review, we seek to give an introductory overview of the present state of the art in modeling of NOM, or representative fragments, at mineral surfaces as well as identifying areas that will present interesting research challenges into the future. In the next section an introduction to computational chemistry is given, which is followed by a summary of simulation studies of NOM and NOM-mineral systems. This is followed by a brief overview of experimental studies on natural and model systems to understand NOM-mineral interactions. The article concludes with an analysis of a future challenge in this area - studying and simulating the surface structure and reactions of NOM at redox active mineral surfaces, which requires an understanding of electron transfer coupled to other physico-chemical processes.

\section{Introduction to Molecular Simulation Methods}

The application of molecular simulation methods to minerals and their interfaces has been reviewed elsewhere [21-25]. A key factor in considering which approach is employed in computational chemistry is the size of the system of interest, the type of information desired, and the time scale of the process of interest (see Figure 1). Inevitably, there is a trade off in accuracy against accessible time and length scales, though multi-scale simulation methods are being developed, which employ either hierarchical [26] or on-the-fly parameter exchange between length and time-scales [27] to try and address these challenges.

Figure 1. Modeling and simulation methods and corresponding system sizes and times. Reprinted with permission from [21].

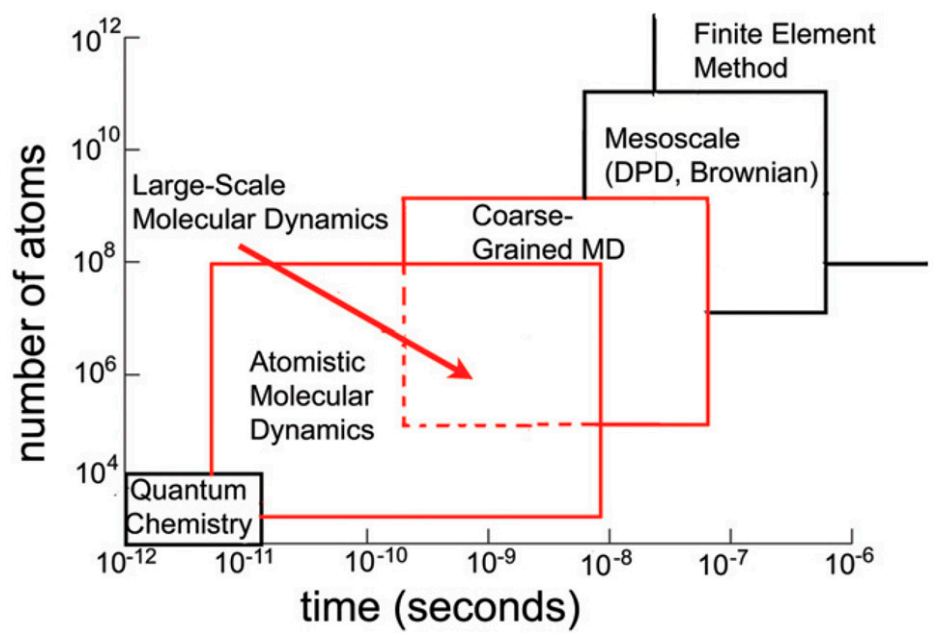

Electronic structure methods such as Hartree-Fock and density functional theory (DFT) include electronic effects (i.e., electron transfer, bond breaking/forming, UV spectroscopy) and represent the highest level of theory, firmly based in quantum mechanics (QM), which can be applied to chemical systems. However, owing to the high computational cost of such methods, their use on NOM or 
NOM-surface applications are restricted to small organic molecules or surface cluster (a cluster is a small, distinct group of representative atoms) models containing representative functional groups, or relevant model compounds where key functionality is included. Such calculations reveal structural properties such as interatomic distances and angles or binding energies that can be used to investigate the effect of organic functional groups on surface interactions. However, one limitation of cluster-based approaches is that the charge on the atoms present can be artificially high, and it is challenging to represent the right degree of substitution in extended mineral structures [28]. Periodic models eliminate the need for small clusters to represent mineral surfaces, as well as allow the use of simpler plane waves over localized basis sets, and DFT results for bulk minerals such as lattice parameters and mechanical properties can be directly compared with experiment for validation [29-32].

Classical simulation methods (so called as they apply classical, non-quantum mechanics based, Newtonian mechanics) require the use of interatomic potential energy expressions (commonly called a force field (FF)) that have been parameterized to reproduce structural and energetic properties from experiment, or quantum calculations. This allows for the simulation of larger and more realistic systems and remains the method of choice for mineral interfaces with bulk aqueous solutions or organic liquids. However, one disadvantage is that to employ these parameters for systems outside the original systems studied, or under different conditions of temperature and/or pressure can lead to inconsistent or inaccurate results. In molecular dynamics (MD) simulation, the time evolution of a molecular system is determined by solving the relevant equations of motion for the specific thermodynamic ensemble of interacting particles/atoms/molecules. The temperature is usually held constant through a thermostat that controls atom velocities, although isoenthalpic methods are available. As such MD is a method that is usually readily comparable to experimental systems, usually carried out under constant pressure conditions.

\section{Simulation Studies of Organic-Mineral Structures}

Though QM simulation methods are hampered by the small atom numbers that can be studied, cluster models of clay mineral surfaces have been used in DFT calculations of organic adsorption. A larger mineral surface cluster was achieved using a molecular mechanics/quantum mechanics (QM/MM) hybrid calculation of acetate binding on a cluster model of kaolinite-type mineral surfaces [33]. More recently, periodic DFT methods have been used to study the binding of organic acids and larger hydrophobic molecules to mineral surfaces [16,34-40], as well as the modeling of reactions of organic molecules at mineral surfaces, including decarboxylation of natural organic matter [16,41].

For larger, more complex, organic molecules, and in particular biomolecular compounds, classical, FF-based simulation methods have enabled the computational chemist to probe interfacial structures and dynamics. Several general FFs have been developed that are transferrable to a wide range of organic and bioorganic molecules [42-44] and aqueous solutions of these molecules. Some of these FFs were parameterized to reproduce the bulk properties of organic liquids [45], which is critical when simulating organic phases near a mineral surface. Several FFs have been developed specifically for use with bulk and layered minerals and their aqueous interfaces, ranging from a computationally simple nonbonded approach (ClayFF [46]), bonded layers (Teppen et al. [47], INTERFACE [48]), and reactive methods (ReaxFF [49]). While mineral-water interfaces have been carefully considered when developing 
these FFs, the simulation of mineral-organic interfaces presents a challenge because no general FF has been developed specifically for mineral-organic interfaces. Instead, MD simulations of such interfaces usually combine a general organic FF with a mineral FF. This untested approach can yield successful comparisons with experiment. In simulating the adsorption of small alcohol and thiol compounds onto $\mathrm{Al}(\mathrm{OH})_{3}$, Greathouse et al. [50] showed that trends in simulated adsorption enthalpies were in excellent agreement with experiment (Figure 2).

Figure 2. Adsorption enthalpy of $\mathrm{C} 1-\mathrm{C} 3$ alcohols and thiols on $\mathrm{Al}(\mathrm{OH})_{3}$ (top); and graphite (middle); surfaces, compared with chemisorption experiments of alcohol adsorption (bottom). Reprinted with permission from [50]. Copyright 2012 American Chemical Society.
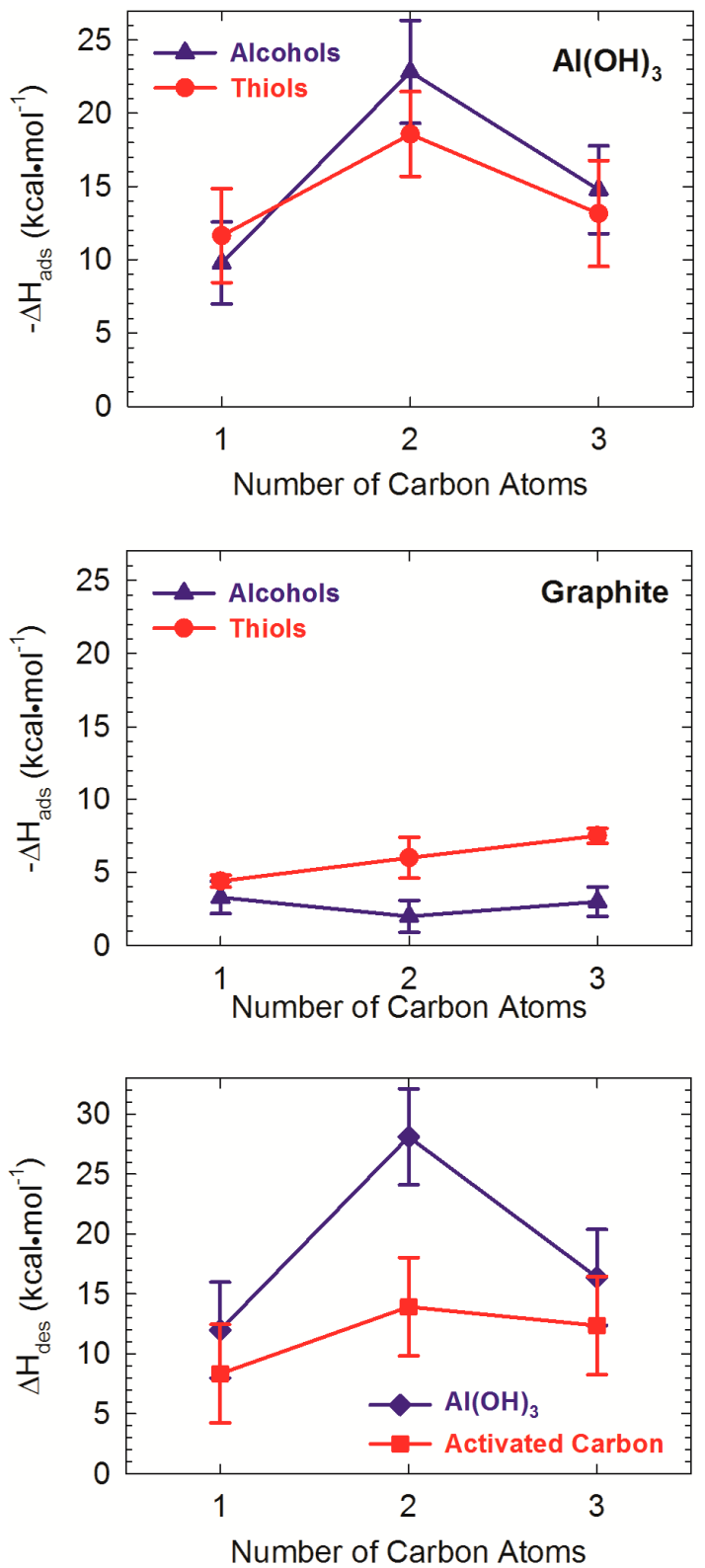

MD simulations have also been used to study the adsorption of small organic molecules [51-54], polymers [55-57], (bio)organic acids [58-60], or entire nucleic acid strands [61-65] onto mineral surfaces. The latter simulations have been particularly noteworthy owing to the size and complexity of the biomolecules studied, with Thyveetil et al. [61] using a high performance computing grid to 
simulate hydrated whole deoxyribonucleic acid (DNA) plasmids of 480 base pairs within a periodic mineral cell of $50 \mathrm{~nm}$ lateral dimensions, and containing 1,157,038 atoms in total. This methodology was further used to probe the structures of different nucleic acids (ribonucleic acid-RNA, peptide nucleic acid (PNA) and DNA) on layered hydroxide and aluminosilicates surfaces [64]. An interesting insight gained from bringing MD techniques to bear on these systems was the novel discovery that a clay mineral surface can rapidly accelerate folding in charged biomolecules, here RNA but feasibly NOM, relative to the same molecule in solution, as illustrated in Figure 3 by Swadling et al. [63]. Minerals can also encourage the unfolding of macromolecules due to the binding of functional groups on mineral surfaces [14].

Figure 3. Simulation snapshot taken from simulations of a folded RNA (nitrogen and phosphorous atoms shown) strand tethered to a montmorillonite surface (silicon atoms shown). Atoms are colored as follows: Si (magenta), Ca (gray), N (blue), P (yellow). Water molecules are hidden to aid in viewing. Reprinted with permission from [63]. Copyright 2010 American Chemical Society.

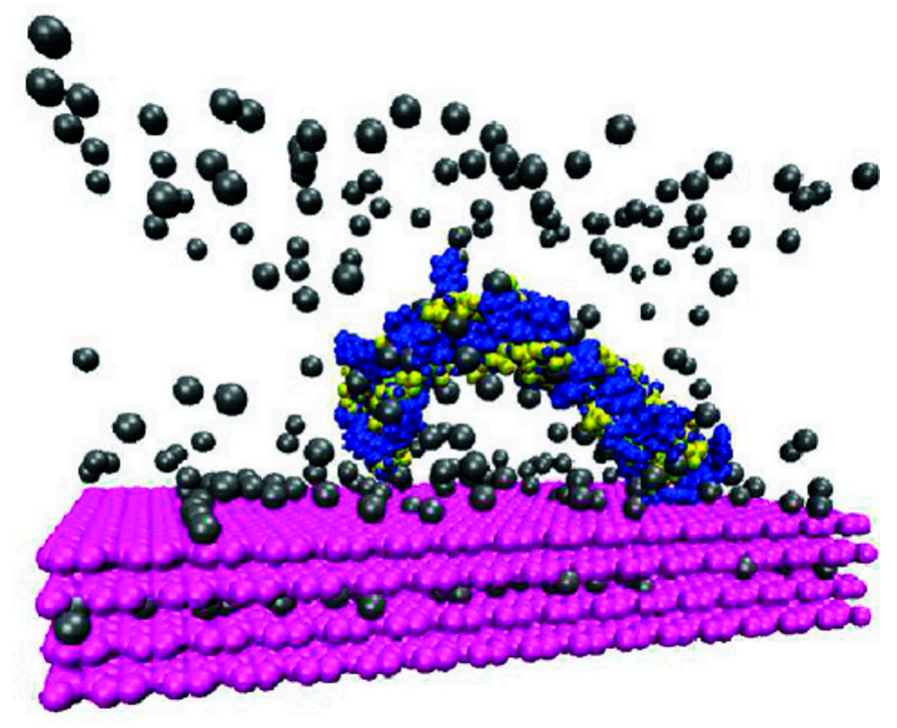

\section{Experimental Studies of Natural Organic Matter-Mineral Structures}

While spectroscopic methods have been used to investigate the structure of NOM adsorbed on mineral surfaces [66-74], using simple organic acids as proxies for NOM can provide valuable insight into possible adsorption mechanisms [75,76]. Carboxylic functional groups are particularly relevant, not only to NOM but also as ligands responsible for binding and transporting potentially toxic elements, owing to many mineral surfaces carrying areas of net positive charge and poly-carboxylate species bridging between these surfaces and dissolved metals during flocculation processes. Furthermore, once formed, metal carboxylates are extremely stable and can rapidly remove carbon into the geosphere. One well-studied example of geoploymerization is the Maillard reaction [77], a sugar-amino-acid condensation reaction, which forms compounds known as melanoidins, catalyzed by redox active minerals, for example manganese oxides such as birnessite [78,79].

The association between stabilized organic matter and clay content in sediments is well documented (e.g., [80]) but far from understood. Kennedy and Wagner [3] have recently argued that smectite is 
particularly important in governing carbon preservation in marine sediments. Zhang et al. [68] noted that $\mathrm{pH}$ increases in clay suspensions after fulvic acid (FA)/humic acid (HA) adsorption suggesting that ligand exchange occurred and FA/HA-clay complexes formed. This was particularly noted for the 2:1 type clay minerals such as smectite and vermiculite, which have surface complexed cations.

More fundamental studies have also been undertaken for NOM-mineral interfaces. Janot et al. [81] have recently studied the adsorption behavior and reactivity of purified HA on $\alpha$-alumina, varying the $\mathrm{pH}$, ionic strength and surface coverage. The authors characterized the complexes formed at a variety of scales, including UV-Vis spectroscopy, spectrophotometric titration and size exclusion chromatography. From the HA concentration in the supernatant and mass balance calculations, "titration curves" were experimentally proposed for the adsorbed fractions, and other measurements allowed insight into protonation state [81]. Such detailed experiments are essential to inform initial configurations for computer simulation.

The role of iron and aluminum oxides, which are adsorbed onto clay particles, is known to play a part in MUC stabilization [68,82-85], although the mechanisms for stabilization have not been determined. Zhang et al. [68] also noted that the higher concentration of iron cations in vermiculite facilitated ligand exchange and cation bridging of carboxyl and hydroxyl functional groups, thus improving adsorption capacity. Finally, Chorover [78] and Jokic [79] have looked at the role of synthetic manganese oxides in stabilizing dissolved organic matter (DOM) and concluded that although they are not as good at adsorbing DOM as other metal oxides or clays, they have a large capacity for fractionating DOM at their surfaces.

\section{Simulations of Natural Organic Matter (NOM) and NOM-Mineral Interfaces}

The broad range of structural features of NOM particles adds difficulty in creating realistic molecular models of these compounds. Fortunately, much of the ion coordination activity in NOM has been shown to occur through several key functional groups, including primarily carboxylate groups but also alcohol/phenol groups [86,87]. A recent review paper outlines current understanding of the important effect of cation bridging in NOM aggregation [87]. Indeed, molecular modeling studies of NOM-mineral interfacial systems indicates that cation bridging between NOM and surface sites predominates over direct interactions between NOM functional groups and the surface [88,89], although humic substances can adsorb directly to clay surfaces in confined interlayer environments [90]. In a recent review of soil humic substances, Sutton and Sposito concluded that NOM consists of a "supramolecular association" of small organic molecules linked by short-range interactions dominated by amide-amide interactions [91]. Regardless of its classification as a single large macromolecule or a cluster of small molecules, the interaction of NOM with hydrophilic sites on mineral surfaces occurs through key functional groups. In fact, various quantum and classical (FF) modeling methods have been used to show that simpler organic compounds containing these key functional groups successfully reproduce the structural, cation binding, and thermodynamic properties of NOM [92-96].

While a number of NOM models based on experimental measurements have been proposed, two recent reviews summarize the few NOM models that have been used in molecular simulations [88,97]. The Temple-Northeastern-Birmingham (TNB) model $[7,86,98]$ of a NOM fragment is an average structure based on spectroscopic and analytical data. It is a good computational analog of the Suwannee 
River NOM often used in experimental studies [99-101]. Other NOM models have been proposed based on pyrolysis measurements [102,103], lignin-carbohydrate complexes [104,105], and fulvic acid models based on oxysuccinic acid structures [106]. Representative structures of these models are shown in Figure 4.

Kalinichev et al. have used MD simulation to test ion bridging models of NOM aggregation in aqueous solution [107,108] and at polyethersulfone membrane surfaces [101]. In aqueous solution, the residence time of calcium ion coordination to NOM carboxylic groups was found to be $0.5 \mathrm{~ns}$, more than an order of magnitude longer than for sodium ion coordination [107,108]. Aggregation of NOM particles occurred in calcium solutions due to ion bridging, but not in sodium solutions where ion bridging did not occur [107,108]. Ion bridging between NOM particles was also found to predominate near polyethersulfone membrane surfaces, while no evidence of NOM surface complexes was seen [101].

Figure 4. Repeating units of proposed natural organic matter (NOM) models: (a) Temple-Northeastern-Birmingham (TNB) [86]; (b) lignin-carboxylate complex [104]; and (c) cutin-lignin-tannin complex [106]. Atoms are colored as followed: $\mathrm{C}$ (gray), $\mathrm{H}$ (white), O (red), N (blue).
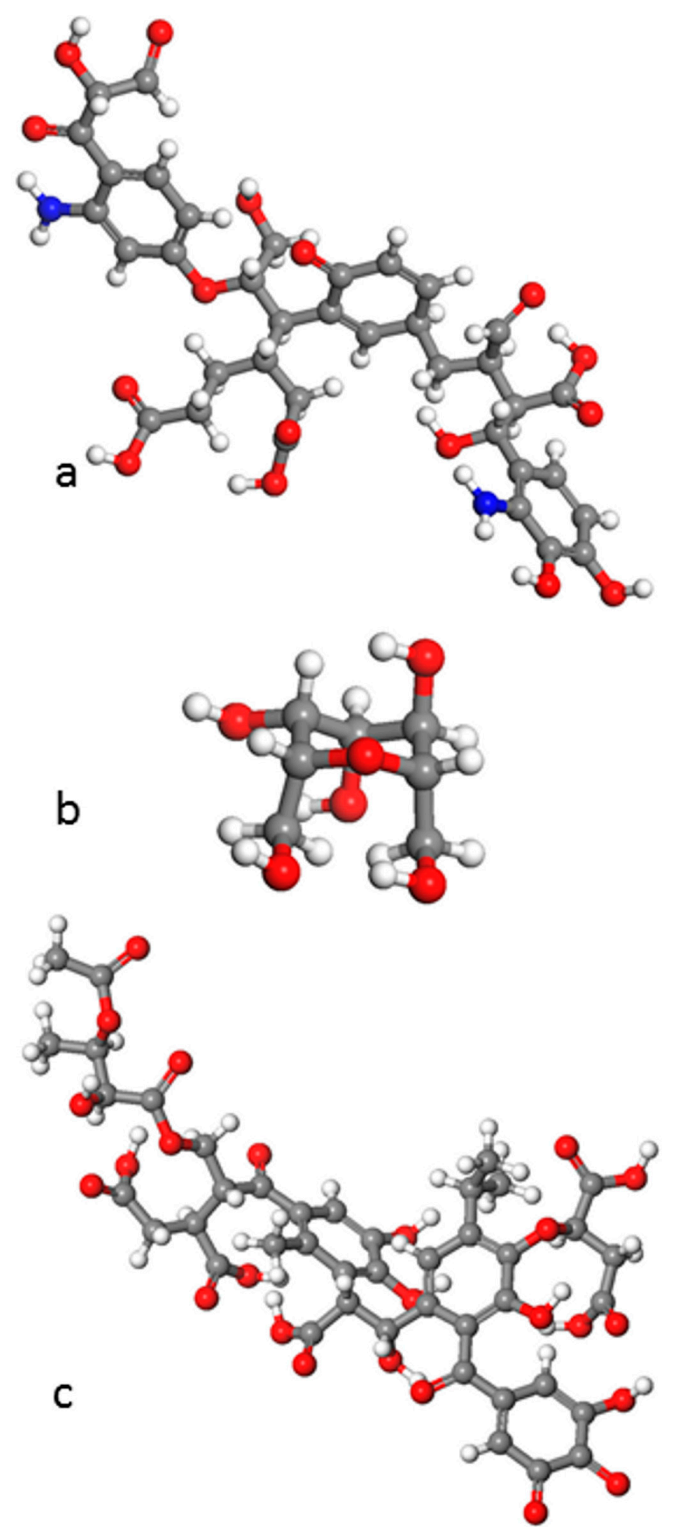
Kalinichev [97] also compared structural features of Ca-NOM complexes using three different organic FFs, and found that all three FFs gave approximately the same structure and binding energy for calcium ion binding at carboxylate groups. This is an important finding in the development of specific organic-mineral FF parameters, and it is consistent with experimental results showing that metal complexation behavior in NOM is similar to well-characterized polymers with similar functionalization [109-113]. The fact that different organic FF parameters yield similar structural and energetic properties for surface complexes indicates a very broad energy minimum for such complexes. Therefore, DFT calculations of such surface complexes might have convergence difficulties if a wide range of conformations have equivalent energy.

\section{Redox Active Mineral-Natural Organic Matter-A Future Challenge}

Whereas simulations have started to add insight into the interactions of natural organic matter, and related model compounds with minerals, and in particular layered minerals, an area that is of key importance is the role of redox active minerals in, firstly, adsorbing organic material, and, secondly, acting as an oxidant to enable the degradation of NOM both at the metal oxide surface and within the mineral matrix when NOM becomes occluded. In this context, iron- and manganese-containing minerals have an important role to play. The environmental significance of dissolved organic matter (DOM) oxidation coupled to Fe(III) and Mn(IV) reduction has been well documented [114], but there remain large uncertainties on how and where organic matter is transformed into different fractions and how these fractions take part in the slow and fast carbon cycles.

\subsection{Role of Iron Based Minerals}

Lalonde et al. [84] have recently highlighted the importance of Fe oxides in stabilizing NOM in marine sediments, but no mechanism was presented for how stabilization occurs. Additionally, it is not clear whether the stabilized organic matter is associated with an iron phase or instead consists of precipitated iron-organic matter complexes. However, ligand exchange between carboxyl groups of NOM and hydroxyl groups on hydrous aluminum and iron oxide surfaces is thought to be the dominant mechanism for NOM adsorption in fresh water sediments [115]. Kaiser et al. [116] found that sorption of dissolved $\mathrm{NOM}$ derived from the oxidative decomposition of lignocellulose to $\mathrm{Al}$ and Fe oxyhydroxides involved relatively strong interactions between surface metals and acidic, particularly aromatic, organic ligands. They observed that the sorption of a large fraction of the NOM was hardly reversible and, as such, cycles of adsorptive and desorptive processes strongly favored the accumulation of the more recalcitrant lignin-derived NOM.

From a computational perspective, a number of recent studies have examined electron transfer processes in iron bearing minerals, which necessitate the use of quantum methods. For example Geatches et al. have looked at how electron transfer occurs in different iron rich nontronite clay forms, using density functional theory [117] and further considering the effect of spin [41], while, recently, Alexandrov et al. [118] studied exchange and conduction processes, also in nontronite. Alexandrov and Rosso [119] further investigated the adsorption and oxidation of iron (II) at the surface of iron rich clay minerals. Wander et al. [120] have studied the dynamics of charge hopping in mixed-valent iron layered hydroxides (commonly called green rusts). Though these studies do not include NOM, the 
potential for studying decomposition of NOM using these techniques is apparent. In a move to start investigating organic-mineral reactions, Geatches et al. [41] have recently studied the decomposition of fatty acid model compounds at the basal surfaces of ferruginous clay.

Owing to the importance of electron transfer processes in mixed valent iron systems, there have been few classical molecular dynamics studies as, inherently, such phenomena could not be captured. However, there have been studies of the adsorption of biomolecules at iron oxide surfaces, for example Qiang et al. [121] have recently studied the interactions between chitosan and $\mathrm{Fe}_{3} \mathrm{O}_{4}$ crystal surfaces. To try and bridge between the time and size scale limitations when studying iron bearing minerals, attempts have been made to develop a reactive force field, where parameters may change according to sets of rules being met [122].

\subsection{Role of Manganese Oxides}

Manganese oxide is one of the most powerful oxidizing agents found on Earth [123]. The most common form of manganese oxide in both soil and marine sediments is birnessite [124]. Birnessite ( $[\mathrm{Na}, \mathrm{Ca}, \mathrm{K}]_{x} \mathrm{Mn}_{2} \mathrm{O}_{4} \cdot 1.5 \mathrm{H}_{2} \mathrm{O}$ ), is often simplified and denoted as $\delta-\mathrm{MnO}_{2}$ in the geochemical literature. Birnessite precipitates in soils mainly as a result of $\mathrm{Mn}^{2+}$ oxidation promoted by bacteria and fungi, and similarly to bacteriogenic ferrihydrite, it forms highly reactive biofilms [125-128] as well as coatings [129,130], nodules and concretions [131].

Solving the crystal structure of birnessite is complicated not only by vacancies in the octahedral sheet, but also by multiple oxidation states of manganese present, namely $\mathrm{Mn}$ (III) and Mn(IV). As a result, very few papers on computational chemistry of birnessite have been published. Only one paper on classical MD simulations of birnessite has appeared, but the reported interlayer structure agreed with diffraction experiments [132]. Quantum methods have been used to investigate the effect of vacancy disordering on structural and energetic properties [133,134] as well as cation adsorption [133,135-137].

Since $\mathrm{Mn}$ is present at $1 / 100$ th of the concentration of $\mathrm{Fe}$ [138], $\delta-\mathrm{MnO}_{2}$ tends to be overlooked. And yet this is a questionable approximation, because firstly, $\delta-\mathrm{MnO}_{2}$ tends to be present as fine-grained aggregates $[129,130]$, it exerts an influence far out of proportion to its total concentration. Secondly, since $\delta-\mathrm{MnO}_{2}$ is a much stronger oxidant than iron oxides, it is more rapidly reduced in anoxic environments taking part in more oxidative reactions than iron. Interestingly, $\mathrm{Mn}$ (III) oxides have higher redox potentials of $1.51 \mathrm{~V}$ ( $c f$. $\mathrm{Mn}(\mathrm{IV})$ oxides $1.23 \mathrm{~V}$ ). The manganese oxidation state in soil is controlled by redox potential and $\mathrm{pH}$. Of the three possible oxidation states that manganese can have when present in soils (II, III and IV), it was thought that the occurrence of $\mathrm{Mn}$ (II) in the environment is thermodynamically favored in the absence of oxygen at low $\mathrm{pH}$, whereas $\mathrm{Mn}$ (III) and $\mathrm{Mn}$ (IV) are favored under aerobic conditions at high $\mathrm{pH}$ [138]. However, Madison et al. [139] has just revised the redox sequence for sediments and soils to include $\mathrm{Mn}$ (III) in solution which can act as both an oxidant and a reductant. This new redox sequence has significant implications for the role of manganese in natural organic matter (NOM) interactions. Since $\mathrm{Mn}$ (III) is present in suboxic zones, this extends the reach of manganese's ability to transform NOM. Unlike iron, which can be removed in anoxic environments as a sulfide, manganese oxides are effectively recycled at oxic/anoxic interfaces [114], and soluble manganese is released which usually ends up re-precipitating at the boundary, or if present as $\mathrm{Mn}(\mathrm{III})$, may go on to oxidize $\mathrm{NOM}$ in its soluble form. For this reason, $\delta-\mathrm{MnO}_{2}$ may play an 
important role in NOM transformations in soil and marine sediments even though it is present at small concentrations.

Birnessite has a low point of zero charge ( $\sim \mathrm{pH} 2)$ [78], and the oxidation of many polar organic compounds by birnessite increases with decreasing $\mathrm{pH}$ [140-144]. The increased oxidation of organic compounds at low $\mathrm{pH}$ has been attributed to:

- Charging of any amide groups present in the organic contaminant resulting in electrostatic attraction to the oxide surface [140];

- Increased sorption of neutral phenolic groups;

- Decrease of the negative charge on $\mathrm{MnO}_{2}$;

- Increased redox potential of the $\mathrm{MnO}_{2} / \mathrm{Mn}^{2+}$ couple [145]; and

- Enhanced removal of $\mathrm{Mn}^{2+}$ from the oxide surface, exposing new reactive sites [146].

Banerjee and Nesbitt [147,148] have described the reduction of birnessite by both oxalate and humate complexes. X-ray photoelectron spectroscopy (XPS) data confirmed that it is the carboxylic group which reacts with the mineral surface and the redox reaction proceeds via a one electron transfer from $\mathrm{Mn}(\mathrm{IV})$ to $\mathrm{Mn}(\mathrm{III})$. There is no evidence for reduction of $\mathrm{Mn}$ (III) to $\mathrm{Mn}$ (II) suggesting that a strong $\mathrm{Mn}$ (III) carboxyl surface complex has formed. Durand et al. [149] studied the binding mechanism of formic acid using XPS, fourier transform infrared spectroscopy (FTIR) and thermogravimetric analysis on amorphous manganese oxides and concluded that the carboxyl group binds to the mineral in a bidentate configuration on an electron neutral surface. However where surface defects such as oxygen vacancies are present, a bridging configuration predominates (Figure 5).

Figure 5. Possible surface complexes for carboxylate directly bound to surface metal atoms (blue) in monodentate, bridging, and bidentate configurations.
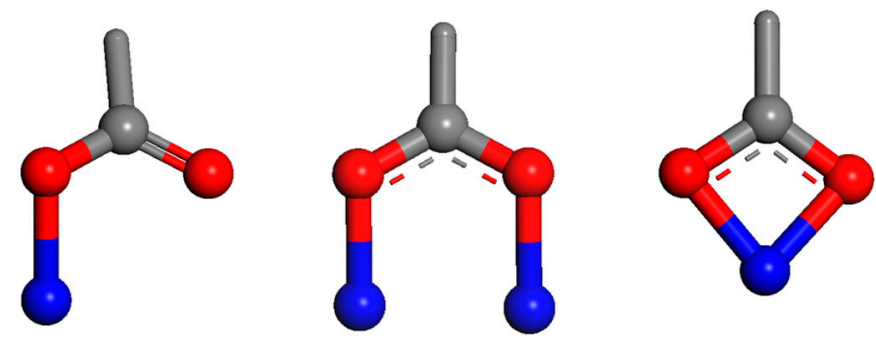

\section{Concluding Remarks}

Through advances in computer simulation hardware and software, as well as analytical technology, the study of molecules as complex as natural organic matter have become accessible, and computational chemists working alongside geoscientists are beginning to add insight into the nano-scale structures of NOM in solution and at mineral surfaces. Through studying simplified NOM macromolecular structures, as well as fragments of NOM and synthetic polymers of relevant functionality, increasing insight is being gained of how NOM interacts at mineral surfaces. Electronic structure simulations can reveal reaction pathways and key interfacial interactions, while classical simulations give structure and dynamics at a molecular-macromolecular scale.

Despite these advances, NOM-mineral interfaces present several areas where much work is still needed, and which are present research challenges to ongoing experimental and computational efforts. 
Additionally, while here we are interested in mineral-NOM interactions, there is also an increasing awareness of the importance of ternary mineral-NOM-metal interactions, which present further challenges [150]. While high-resolution X-ray adsorption spectroscopy quantifies nearest neighbor structure at the atomistic level, there is a need for more such experimental studies of organic interactions with mineral surfaces. Additionally, NOM can often be present in only small quantities (e.g., monolayer) at a mineral surface and in irregular patterns, complicating the study of NOM-mineral interfaces using such methods.

The emergent interest in organo-manganese oxide systems in technological applications also bodes well for increased experimental research on how model organic molecules interact with manganese oxide surfaces. Since manganese oxides act as cation exchange minerals, the exchange of inorganic cations such as sodium and potassium for organo-ammonium species can be attained to afford new materials with enhanced adsorption [151] or electrical [152] properties, as well as potentially interesting and novel crystal morphologies [153]. In the latter case, Ahmed and Huang [153] were able to use polyethylene glycol-melamine-formaldehyde to grow birnessite nanotubes and nanorods. Further materials applications have involved carbon nanotube manganese oxide composites for electrode applications [154].

A significant computational challenge is the coupling of differing phenomena, allowing access to structure, dynamics and reactivity at interfaces. A second computational challenge is extending the timescale of simulations to enable the complex macromolecules in NOM to reach equilibrated, low energy structures. For the first of these challenges, the elements are there; research has been carried out on electron transfer processes in minerals, and more is understood regarding the nature and composition of NOM. The second challenge is presently limited to a few enhanced sampling MD methods $[155,156]$. Biased kinetic Monte Carlo methods can also be used to quickly search through a constrained set of possible reaction coordinates, though this technique has, hitherto, been mainly used to probe small molecules at catalyst surfaces [157].

Just a decade ago, a simulation of NOM systems would have required access to considerable high performance computing resources, whereas now, owing to rapid developments in computational performance as well as efficient codes, NOM systems are able to be simulated, and such approaches will both be informed by, and inform, data from the latest generation of experiments. For example, synchrotron-based mass spectrometry allows the simultaneous collection of molecular level data on organic species, and information on the mineral structure on which they are adsorbed [158]. Neutron diffraction of layered minerals intercalated with polymers is another promising experimental approach to obtain interfacial structure [159]. Through collaborative research using methods such as these, we presently stand at a point where research into NOM interactions is likely to grow rapidly.

\section{Acknowledgments}

This work is supported by the U.S. Department of Energy, Office of Basic Energy Sciences, Geosciences Research Program. Sandia National Laboratories is a multi-program laboratory managed and operated by Sandia Corporation, a wholly owned subsidiary of Lockheed Martin Corporation, for the U.S. Department of Energy's National Nuclear Security Administration under contract DE-AC04-94AL85000. Support from Durham University (Department of Earth Sciences and Institute of Advanced Study) as well as the EU are gratefully acknowledged. 


\section{Author Contributions}

All authors were involved in writing and revising all parts of the manuscript.

\section{Conflicts of Interest}

The authors declare no conflict of interest.

\section{References}

1. Senesi, N.; Xing, B.; Huang, P.M. Biophysico-Chemical Processes Involving Natural Nonliving Organic Matter in Environmental Systems; John Wiley and Sons: Hoboken, NJ, USA, 2009.

2. Keil, R.G.; Mayer, L.M. Mineral matrices and organic matter. In Treatise on Geochemistry, 2nd ed.; Holland, H.D., Turekian, K.K., Eds.; Elsevier: Oxford, UK, 2014; pp. 337-359.

3. Kennedy, M.J.; Wagner, T. Clay mineral continental amplifier for marine carbon sequestration in a greenhouse ocean. Proc. Natl. Acad. Sci. USA 2011, 108, 9776-9781.

4. Polubesova, T.; Chefetz, B. DOM-affected transformation of contaminants on mineral surfaces: A review. Crit. Rev. Env. Sci. Technol. 2014, 44, 223-254.

5. Matilainen, A.; Vepsalainen, M.; Sillanpaa, M. Natural organic matter removal by coagulation during drinking water treatment: A review. Adv. Colloid Interface Sci. 2010, 159, 189-197.

6. Al-Amoudi, A.S. Factors affecting natural organic matter (NOM) and scaling fouling in NF membranes: A review. Desalination 2010, 259, 1-10.

7. Jansen, S.A.; Malaty, M.; Nwabara, S.; Johnson, E.; Ghabbour, E.; Davies, G.; Varnum, J.M. Structural modeling in humic acids. Mater. Sci. Eng. C Bio. S. 1996, 4, 175-179.

8. Snoeyink, V.L.; Jenkins, D. Water Chemistry; John Wiley and Sons: New York, NY, USA, 1980.

9. Hedges, J.I.; Eglinton, G.; Hatcher, P.G.; Kirchman, D.L.; Arnosti, C.; Derenne, S.; Evershed, R.P.; Kogel-Knabner, I.; de Leeuw, J.W.; Littke, R.; et al. The molecularly-uncharacterized component of nonliving organic matter in natural environments. Org. Geochem. 2000, 31, 945-958.

10. Burdige, D.J. Preservation of organic matter in marine sediments: Controls, mechanisms, and an imbalance in sediment organic carbon budgets? Chem. Rev. 2007, 107, 467-485.

11. Von Lutzow, M.; Kogel-Knabner, I.; Ekschmitt, K.; Matzner, E.; Guggenberger, G.; Marschner, B.; Flessa, H. Stabilization of organic matter in temperate soils: Mechanisms and their relevance under different soil conditions-A review. Eur. J. Soil Sci. 2006, 57, 426-445.

12. Weber, W.J., Jr.; McGinley, P.M.; Katz, L.E. A distributed reactivity model for sorption by soils and sediments. 1. Conceptual basis and equilibrium assessments. Environ. Sci. Technol. 1992, 26, 1955-1962.

13. Vandenbroucke, M.; Largeau, C. Kerogen origin, evolution and structure. Org. Geochem. 2007, $38,719-833$.

14. Collins, M.J.; Bishop, A.N.; Farrimond, P. Sorption by mineral surfaces—Rebirth of the classical condensation pathway for kerogen formation. Geochim. Cosmochim. Acta 1995, 59, 2387-2391.

15. Brown, G.E.; Calas, G. Mineral-aqueous solution interfaces and their impact on the environment. Geochem. Perspect. 2012, 1, 483-742. 
16. Geatches, D.L.; Clark, S.J.; Greenwell, H.C. Role of clay minerals in oil-forming reactions. J. Phys. Chem. A 2010, 114, 3569-3575.

17. Wu, L.M.; Zhou, C.H.; Keeling, J.; Tong, D.S.; Yu, W.H. Towards an understanding of the role of clay minerals in crude oil formation, migration and accumulation. Earth Sci. Rev. 2012, 115, 373-386.

18. Chen, B.; Evans, J.R.G.; Greenwell, H.C.; Boulet, P.; Coveney, P.V.; Bowden, A.A.; Whiting, A. A critical appraisal of polymer-clay nanocomposites. Chem. Soc. Rev. 2008, 37, 568-594.

19. Sels, B.F.; de vos, D.E.; Jacobs, P.A. Hydrotalcite-like anionic clays in catalytic organic reactions. Catal. Rev. Sci. Eng. 2001, 43, 443-488.

20. Debecker, D.P.; Gaigneaux, E.M.; Busca, G. Exploring, tuning, and exploiting the basicity of hydrotalcites for applications in heterogeneous catalysis. Chem. Eur. J. 2009, 15, 3920-3935.

21. Suter, J.L.; Anderson, R.L.; Greenwell, H.C.; Coveney, P.V. Recent advances in large-scale atomistic and coarse-grained molecular dynamics simulation of clay minerals. J. Mater. Chem. 2009, 19, 2482-2493.

22. Geysermans, P.; Noguera, C. Advances in atomistic simulations of mineral surfaces. J. Mater. Chem. 2009, 19, 7807-7821.

23. Greenwell, H.C.; Jones, W.; Coveney, P.V.; Stackhouse, S. On the application of computer simulation techniques to anionic and cationic clays: A materials chemistry perspective. J. Mater. Chem. 2006, 16, 708-723.

24. Anderson, R.L.; Ratcliffe, I.; Greenwell, H.C.; Williams, P.A.; Cliffe, S.; Coveney, P.V. Clay swelling-A challenge in the oilfield. Earth Sci. Rev. 2010, 98, 201-216.

25. Cygan, R.T.; Greathouse, J.A.; Heinz, H.; Kalinichev, A.G. Molecular models and simulations of layered minerals. J. Mater. Chem. 2009, 19, 2470-2481.

26. Lyubartsev, A.; Tu, Y.Q.; Laaksonen, A. Hierarchical multiscale modelling scheme from first principles to mesoscale. J. Comput. Theor. Nanosci. 2009, 6, 951-959.

27. Moras, G.; Choudhury, R.; Kermode, J.R.; CsÁnyi, G.; Payne, M.C.; de Vita, A. Hybrid quantum/classical modeling of material systems: The "learn on the fly" molecular dynamics scheme. In Trends in Computational Nanomechanics: Transcending Length and Time Scales; Dumitrica, T., Ed.; Springer Netherlands: Dordrecth, The Netherlands, 2010; Volume 9, pp. 1-23.

28. Boulet, P.; Greenwell, H.C.; Stackhouse, S.; Coveney, P.V. Recent advances in understanding the structure and reactivity of clays using electronic structure calculations. J. Mol. Struct. 2006, $762,33-48$.

29. Larentzos, J.P.; Greathouse, J.A.; Cygan, R.T. An ab initio and classical molecular dynamics investigation of the structural and vibrational properties of talc and pyrophyllite. J. Phys. Chem. C 2007, 111, 12752-12759.

30. Ortega-Castro, J.; Hernandez-Haro, N.; Hernandez-Laguna, A.; Sainz-Diaz, C.I. DFT calculation of cystallographic properties of dioctahedral 2:1 phyllosilicates. Clay Miner. 2008, 43, 351-361.

31. Berghout, A.; Tunega, D.; Zaoui, A. Density functional theory (DFT) study of the hydration steps of $\mathrm{Na}^{+} / \mathrm{Mg}^{2+} / \mathrm{Ca}^{2+} / \mathrm{Sr}^{2+} / \mathrm{Ba}^{2+}$-exchanged montmorillonites. Clays Clay Miner. 2010, 58, $174-187$. 
32. Voora, V.K.; Al-Saidi, W.A.; Jordan, K.D. Density functional theory study of pyrophyllite and M-montmorillonites $(\mathrm{M}=\mathrm{Li}, \mathrm{Na}, \mathrm{K}, \mathrm{Mg}$, and $\mathrm{Ca})$ : Role of dispersion interactions. J. Phys. Chem. A 2011, 115, 9695-9703.

33. Gerzabek, M.H.; Aquino, A.J.A.; Haberhauer, G.; Tunega, D.; Lischka, H. Molecular modelling-opportunities for soil research. Bodenkultur 2001, 52, 133-146.

34. Aquino, A.J.A.; Tunega, D.; Gerzabek, M.H.; Lischka, H. Modeling catalytic effects of clay mineral surfaces on peptide bond formation. J. Phys. Chem. B 2004, 108, 10120-10130.

35. Tunega, D.; Gerzabek, M.H.; Haberhauer, G.; Totsche, K.U.; Lischka, H. Model study on sorption of polycyclic aromatic hydrocarbons to goethite. J. Colloid Interface Sci. 2009, 330, $244-249$.

36. Liu, X.D.; Lu, X.C.; Wang, R.C.; Zhou, H.Q.; Xu, S.J. Surface complexes of acetate on edge surfaces of 2:1 type phyllosilicate: Insights from density functional theory calculation. Geochim. Cosmochim. Acta 2008, 72, 5896-5907.

37. Geatches, D.L.; Jacquet, A.; Clark, S.J.; Greenwell, H.C. Monomer adsorption on kaolinite: Modeling the essential ingredients. J. Phys. Chem. C 2012, 116, 22365-22374.

38. Aquino, A.J.A.; Tunega, D.; Haberhauer, G.; Gerzabek, M.H.; Lischka, H. Adsorption of organic substances on broken clay surfaces: A quantum chemical study. J. Comput. Chem. 2003, 24, $1853-1863$.

39. Kwon, K.D.; Vadillo-Rodriguez, V.; Logan, B.E.; Kubicki, J.D. Interactions of biopolymers with silica surfaces: Force measurements and electronic structure calculation studies. Geochim. Cosmochim. Acta 2006, 70, 3803-3819.

40. Lee, B.H.; Lee, S.K. Effect of lattice topology on the adsorption of benzyl alcohol on kaolinite surfaces: Quantum chemical calculations of geometry optimization, binding energy, and NMR chemical shielding. Am. Mineral. 2009, 94, 1392-1404.

41. Geatches, D.L.; Clark, S.J.; Greenwell, H.C. DFT plus U investigation of the catalytic properties of ferruginous clay. Am. Mineral. 2013, 98, 132-140.

42. Dauber-Osguthorpe, P.; Roberts, V.A.; Osguthorpe, D.J.; Wolff, J.; Genest, M.; Hagler, A.T. Structure and energetics of ligand binding to proteins: Escherichia coli dihydrofolate reductase-trimethoprim, a drug-receptor system. Proteins Struct. Funct. Genet. 1988, 4, 31-47.

43. Jorgensen, W.L.; Tiradorives, J. The OPLS potential functions for proteins. Energy minimizations for crystals of cyclic peptides and crambin. J. Am. Chem. Soc. 1988, 110, 1657-1666.

44. Brooks, B.R.; Bruccoleri, R.E.; Olafson, B.D.; States, D.J.; Swaminathan, S.; Karplus, M. CHARMM-A program for macromolecular energy, minimization, and dynamics calculations. J. Comput. Chem. 1983, 4, 187-217.

45. Jorgensen, W.L.; Maxwell, D.S.; TiradoRives, J. Development and testing of the OPLS all-atom force field on conformational energetics and properties of organic liquids. J. Am. Chem. Soc. 1996, 118, 11225-11236.

46. Cygan, R.T.; Liang, J.-J.; Kalinichev, A.G. Molecular models of hydroxide, oxyhydroxide, and clay phases and the development of a general force field. J. Phys. Chem. B 2004, 108, 1255-1266.

47. Teppen, B.J.; Rasmussen, K.R.; Bertsch, P.M.; Miller, D.M.; Schafer, L. Molecular dynamics modeling of clay minerals. 1. Gibbsite, kaolinite, pyrophillite, and beidellite. J. Phys. Chem. B 1997, 101, 1579-1587. 
48. Heinz, H.; Lin, T.J.; Mishra, R.K.; Emami, F.S. Thermodynamically consistent force fields for the assembly of inorganic, organic, and biological nanostructures: The INTERFACE force field. Langmuir 2013, 29, 1754-1765.

49. Pitman, M.C.; van Duin, A.C.T. Dynamics of confined reactive water in smectite clay-zeolite composites. J. Am. Chem. Soc. 2012, 134, 3042-3053.

50. Greathouse, J.A.; Hart, D.B.; Ochs, M.E. Alcohol and thiol adsorption on (oxy)hydroxide and carbon surfaces: Molecular dynamics simulation and desorption experiments. J. Phys. Chem. C 2012, 116, 26756-26764.

51. Veteska, M.; Pospisil, M.; Melanova, K.; Benes, L.; Zima, V. Structure analysis of hydrotalcite intercalated with pyrenetetrasulfonate; experiments and molecular modelling. J. Mol. Model. 2008, 14, 1119-1129.

52. Kovar, P.; Pospisil, M.; Kafunkova, E.; Lang, K.; Kovanda, F. Mg-Al layered double hydroxide intercalated with porphyrin anions: Molecular simulations and experiments. J. Mol. Model. 2010, 16, 223-233.

53. Praus, P.; Veteska, M.; Pospisil, M. Adsorption of phenol and aniline on natural and organically modified montmorillonite: Experiment and molecular modelling. Mol. Simul. 2011, 37, 964-974.

54. Liu, C.; Li, H.; Johnston, C.T.; Boyd, S.A.; Teppen, B.J. Relating clay structural factors to dioxin adsorption by smectites: Molecular dynamics simulations. Soil Sci. Soc. Am. J. 2012, 76, 110-120.

55. Greenwell, H.C.; Bowden, A.A.; Chen, B.Q.; Boulet, P.; Evans, J.R.G.; Coveney, P.V.; Whiting, A. Intercalation and in situ polymerization of poly (alkylene oxide) derivatives within $\mathrm{M}^{+}$-montmorillonite (M = Li, Na, K). J. Mater. Chem. 2006, 16, 1082-1094.

56. Anderson, R.L.; Greenwell, H.C.; Suter, J.L.; Coveney, P.V.; Thyveetil, M.A. Determining materials properties of natural composites using molecular simulation. J. Mater. Chem. 2009, 19, 7251-7262.

57. Kulhankova, L.; Tokarsky, J.; Peikertova, P.; Kutlakova, K.M.; Ivanek, L.; Capkova, P. Montmorillonite intercalated by conducting polyanilines. J. Phys. Chem. Solids 2012, 73, $1530-1533$.

58. Kumar, P.P.; Kalinichev, A.G.; Kirkpatrick, R.J. Hydration, swelling, interlayer structure, and hydrogen bonding in organolayered double hydroxides: Insights from molecular dynamics simulation of citrate-intercalated hydrotalcite. J. Phys. Chem. B 2006, 110, 3841-3844.

59. Kumar, P.P.; Kalinichev, A.G.; Kirkpatrick, R.J. Molecular dynamics simulation of the energetics and structure of layered double hydroxides intercalated with carboxylic acids. J. Phys. Chem. C 2007, 111, 13517-13523.

60. Kalinichev, A.G.; Kumar, P.P.; Kirkpatrick, R.J. Molecular dynamics computer simulations of the effects of hydrogen bonding on the properties of layered double hydroxides intercalated with organic acids. Philos. Mag. 2010, 90, 2475-2488.

61. Thyveetil, M.A.; Coveney, P.V.; Greenwell, H.C.; Suter, J.L. Computer simulation study of the structural stability and materials properties of DNA-intercalated layered double hydroxides. J. Am. Chem. Soc. 2008, 130, 4742-4756.

62. Thyveetil, M.A.; Coveney, P.V.; Greenwell, H.C.; Suter, J.L. Role of host layer flexibility in DNA guest intercalation revealed by computer simulation of layered nanomaterials. J. Am. Chem. Soc. 2008, 130, 12485-12495. 
63. Swadling, J.B.; Coveney, P.V.; Greenwell, H.C. Clay minerals mediate folding and regioselective interactions of RNA: A large-scale atomistic simulation study. J. Am. Chem. Soc. 2010, 132, 13750-13764.

64. Swadling, J.B.; Coveney, P.V.; Greenwell, H.C. Stability of free and mineral-protected nucleic acids: Implications for the RNA world. Geochim. Cosmochim. Acta 2012, 83, 360-378.

65. Swadling, J.B.; Suter, J.L.; Greenwell, H.C.; Coveney, P.V. Influence of surface chemistry and charge on mineral-RNA interactions. Langmuir 2013, 29, 1573-1583.

66. Lee, S.S.; Fenter, P.; Park, C.; Nagy, K.L. Fulvic acid sorption on muscovite mica as a function of $\mathrm{pH}$ and time using in situ X-ray reflectivity. Langmuir 2008, 24, 7817-7829.

67. Lee, S.S.; Park, C.; Fenter, P.; Sturchio, N.C.; Nagy, K.L. Competitive adsorption of strontium and fulvic acid at the muscovite-solution interface observed with resonant anomalous X-ray reflectivity. Geochim. Cosmochim. Acta 2010, 74, 1762-1776.

68. Zhang, L.C.; Luo, L.; Zhang, S.Z. Integrated investigations on the adsorption mechanisms of fulvic and humic acids on three clay minerals. Colloids Surf. A 2012, 406, 84-90.

69. Ha, J.Y.; Yoon, T.H.; Wang, Y.G.; Musgrave, C.B.; Brown, G.E. Adsorption of organic matter at mineral/water interfaces: 7. ATR-FTIR and quantum chemical study of lactate interactions with hematite nanoparticles. Langmuir 2008, 24, 6683-6692.

70. Yoon, T.H.; Johnson, S.B.; Brown, G.E. Adsorption of organic matter at mineral/water interfaces. IV. Adsorption of humic substances at boehmite/water interfaces and impact on boehmite dissolution. Langmuir 2005, 21, 5002-5012.

71. Conte, P.; Abbate, C.; Baglieri, A.; Negre, M.; De Pasquale, C.; Alonzo, G.; Gennari, M. Adsorption of dissolved organic matter on clay minerals as assessed by infra-red, CPMAS C-13 NMR spectroscopy and low field T-1 NMR relaxometry. Org. Geochem. 2011, 42, 972-977.

72. Kang, S.; Xing, B. Humic acid fractionation upon sequential adsorption onto goethite. Langmuir 2008, 24, 2525-2531.

73. Spagnuolo, M.; Jacobson, A.R.; Baveye, P. Electron paramagnetic resonance analysis of the distribution of a hydrophobic spin probe in suspensions of humic acids, hectorite, and aluminum hydroxide-humate-hectorite complexes. Environ. Toxicol. Chem. 2005, 24, 2435-2444.

74. Kaiser, K.; Guggenberger, G.; Haumaier, L.; Zech, W. Dissolved organic matter sorption on subsoils and minerals studied by C-13-NMR and drift spectroscopy. Eur. J. Soil Sci. 1997, 48, 301-310.

75. Evanko, C.R.; Dzombak, D.A. Influence of structural features on sorption of NOM-analogue organic acids to goethite. Environ. Sci. Technol. 1998, 32, 2846-2855.

76. Ali, M.A.; Dzombak, D.A. Competitive sorption of simple organic acids and sulfate on goethite. Environ. Sci. Technol. 1996, 30, 1061-1071.

77. Maillard, L.C. Formation of humic matters by the effect of polypeptides on sugars. C. R. Hebd. Seances Acad. Sci. 1913, 156, 1159-1160.

78. Chorover, J.; Amistadi, M.K. Reaction of forest floor organic matter at goethite, birnessite and smectite surfaces. Geochim. Cosmochim. Acta 2001, 65, 95-109.

79. Jokic, A.; Frenkel, A.I.; Vairavamurthy, M.A.; Huang, P.M. Birnessite catalysis of the Maillard reaction: Its significance in natural humification. Geophys. Res. Lett. 2001, 28, 3899-3902. 
80. Keil, R.G.; Montlucon, D.B.; Prahl, F.G.; Hedges, J.I. Sorptive preservation of labile organic-matter in marine-sediments. Nature 1994, 370, 549-552.

81. Janot, N.; Reiller, P.E.; Zheng, X.; Croue, J.-P.; Benedetti, M.F. Characterization of humic acid reactivity modifications due to adsorption onto alpha- $\mathrm{Al}_{2} \mathrm{O}_{3}$. Water Res. 2012, 46, 731-740.

82. Schnitzer, M.; Kodama, H. Interactions between organic and inorganic components in particle-size fractions separated from 4 soils. Soil Sci. Soc. Am. J. 1992, 56, 1099-1105.

83. Saidy, A.R.; Smernik, R.J.; Baldock, J.A.; Kaiser, K.; Sanderman, J. The sorption of organic carbon onto differing clay minerals in the presence and absence of hydrous iron oxide. Geoderma 2013, 209, 15-21.

84. Lalonde, K.; Mucci, A.; Ouellet, A.; Gelinas, Y. Preservation of organic matter in sediments promoted by iron. Nature 2012, 483, 198-200.

85. Wiseman, C.L.S.; Puttmann, W. Soil organic carbon and its sorptive preservation in central germany. Eur. J. Soil Sci. 2005, 56, 65-76.

86. Davies, G.; Fataftah, A.; Cherkasskiy, A.; Ghabbour, E.A.; Radwan, A.; Jansen, S.A.; Kolla, S.; Paciolla, M.D.; Sein, L.T.; Buermann, W.; et al. Tight metal binding by humic acids and its role in biomineralization. J. Chem. Soc. Dalton Trans. 1997, 4047-4060.

87. Kunhi Mouvenchery, Y.; Kucerik, J.; Diehl, D.; Schaumann, G.E. Cation-mediated cross-linking in natural organic matter: A review. Rev. Env. Sci. Biotechnol. 2012, 11, 41-54.

88. Schaumann, G.E.; Thiele-Bruhn, S. Molecular modeling of soil organic matter: Squaring the circle? Geoderma 2011, 166, 1-14.

89. Perry, T.D.; Cygan, R.T.; Mitchell, R. Molecular models of alginic acid: Interactions with calcium ions and calcite surfaces. Geochim. Cosmochim. Acta 2006, 70, 3508-3532.

90. Sutton, R.; Sposito, G. Molecular simulation of humic substance-Ca-montmorillonite complexes. Geochim. Cosmochim. Acta 2006, 70, 3566-3581.

91. Sutton, R.; Sposito, G. Molecular structure in soil humic substances: The new view. Environ. Sci. Technol. 2005, 39, 9009-9015.

92. Aquino, A.J.A.; Tunega, D.; Pasalic, H.; Haberhauer, G.; Gerzabek, M.H.; Lischka, H. The thermodynamic stability of hydrogen bonded and cation bridged complexes of humic acid models - A theoretical study. Chem. Phys. 2008, 349, 69-76.

93. Aquino, A.J.A.; Tunega, D.; Schaumann, G.E.; Haberhauer, G.; Gerzabek, M.H.; Lischka, H. Stabilizing capacity of water bridges in nanopore segments of humic substances: A theoretical investigation. J. Phys. Chem. C 2009, 113, 16468-16475.

94. Aquino, A.J.A.; Tunega, D.; Schaumann, G.E.; Haberhauer, G.; Gerzabek, M.H.; Lischka, H. The functionality of cation bridges for binding polar groups in soil aggregates. Int. J. Quantum Chem. 2011, 111, 1531-1542.

95. Aquino, A.J.A.; Tunega, D.; Pasalic, H.; Schaumann, G.E.; Haberhauer, G.; Gerzabek, M.H.; Lischka, H. Molecular dynamics simulations of water molecule-bridges in polar domains of humic acids. Environ. Sci. Technol. 2011, 45, 8411-8419.

96. Aquino, A.J.A.; Tunega, D.; Pasalic, H.; Schaumann, G.E.; Haberhauer, G.; Gerzabek, M.H.; Lischka, H. Study of solvent effect on the stability of water bridge-linked carboxyl groups in humic acid models. Geoderma 2011, 169, 20-26. 
97. Kalinichev, A.G., Molecular models of natural organic matter and its colloidal aggregation in aqueous solutions: Challenges and opportunities for computer simulations. Pure Appl. Chem. 2013, 85, 149-158.

98. Sein, L.T.; Varnum, J.M.; Jansen, S.A. Conformational modeling of a new building block of humic acid: Approaches to the lowest energy conformer. Environ. Sci. Technol. 1999, 33, $546-552$.

99. $\mathrm{Xu}, \mathrm{X}$; Kalinichev, A.G.; Kirkpatrick, R.J. ${ }^{133} \mathrm{Cs}$ and ${ }^{35} \mathrm{Cl} \mathrm{NMR}$ spectroscopy and molecular dynamics modeling of $\mathrm{Cs}^{+}$and $\mathrm{Cl}^{-}$complexation with natural organic matter. Geochim. Cosmochim. Acta 2006, 70, 4319-4331.

100. Kalinichev, A.G.; Kirkpatrick, R.J. Molecular dynamics simulation of cationic complexation with natural organic matter. Eur. J. Soil Sci. 2007, 58, 909-917.

101. Ahn, W.Y.; Kalinichev, A.G.; Clark, M.M. Effects of background cations on the fouling of polyethersulfone membranes by natural organic matter: Experimental and molecular modeling study. J. Membr. Sci. 2008, 309, 128-140.

102. Schulten, H.R.; Schnitzer, M. Chemical model structures for soil organic matter and soils. Soil Sci. 1997, 162, 115-130.

103. Schulten, H.R.; Schnitzer, M. A state-of-the-art structural concept for humic substances. Naturwissenschaften 1993, 80, 29-30.

104. Shevchenko, S.M.; Bailey, G.W.; Akim, L.G. The conformational dynamics of humic polyanions in model organic and organo-mineral aggregates. J. Mol. Struct. 1999, 460, 179-190.

105. Shevchenko, S.M.; Bailey, G.W. Modeling sorption of soil organic matter on mineral surfaces: Wood-derived polymers on mica. Supramol. Sci. 1998, 5, 143-157.

106. Leenheer, J.A.; Brown, G.K.; MacCarthy, P.; Cabaniss, S.E. Models of metal binding structures in fulvic acid from the Suwannee River, Georgia. Environ. Sci. Technol. 1998, 32, 2410-2416.

107. Iskrenova-Tchoukova, E.; Kalinichev, A.G.; Kirkpatrick, R.J. Metal cation complexation with natural organic matter in aqueous solutions: Molecular dynamics simulations and potentials of mean force. Langmuir 2010, 26, 15909-15919.

108. Kalinichev, A.G.; Iskrenova-Tchoukova, E.; Ahn, W.-Y.; Clark, M.M.; Kirkpatrick, R.J. Effects of $\mathrm{Ca}^{2+}$ on supramolecular aggregation of natural organic matter in aqueous solutions: A comparison of molecular modeling approaches. Geoderma 2011, 169, 27-32.

109. Kirishima, A.; Tanaka, K.; Niibori, Y.; Tochiyama, O. Complex formation of calcium with humic acid and polyacrylic acid. Radiochim. Acta 2002, 90, 555-561.

110. Plaschke, M.; Rothe, J.; Armbruster, M.K.; Denecke, M.A.; Naber, A.; Geckeis, H. Humic acid metal cation interaction studied by spectromicroscopy techniques in combination with quantum chemical calculations. J. Synchrotron Radiat. 2010, 17, 158-165.

111. Roger, G.M.; Durand-Vidal, S.; Bernard, O.; Meriguet, G.; Altmann, S.; Turq, P. Characterization of humic substances and polyacrylic acid: A high precision conductimetry study. Colloids Surf. A 2010, 356, 51-57.

112. Crea, F.; Giacalone, A.; Gianguzza, A.; Piazzese, D.; Sammartano, S. Modelling of natural and synthetic polyelectrolyte interactions in natural waters by using SIT, Pitzer and ion pairing approaches. Mar. Chem. 2006, 99, 93-105. 
113. Crea, F.; de Stefano, C.; Gianguzza, A.; Pettignano, A.; Piazzese, D.; Sammartano, S. Acid-base properties of synthetic and natural polyelectrolytes: Experimental results and models for the dependence on different aqueous media. J. Chem. Eng. Data 2009, 54, 589-605.

114. Lovley, D.R. Dissimilatory Fe(III) and Mn(IV) reduction. Microbiol. Rev. 1991, 55, 259-287.

115. Gu, B.H.; Schmitt, J.; Chen, Z.H.; Liang, L.Y.; McCarthy, J.F., Adsorption and desorption of natural organic-matter on iron-oxide - mechanisms and models. Environ. Sci. Technol. 1994, 28, $38-46$.

116. Kaiser, K.; Guggenberger, G. The role of DOM sorption to mineral surfaces in the preservation of organic matter in soils. Org. Geochem. 2000, 31, 711-725.

117. Geatches, D.L.; Clark, S.J.; Greenwell, H.C. Iron reduction in nontronite-type clay minerals: Modelling a complex system. Geochim. Cosmochim. Acta 2012, 81, 13-27.

118. Alexandrov, V.; Neumann, A.; Scherer, M.M.; Rosso, K.M. Electron exchange and conduction in nontronite from first-principles. J. Phys. Chem. C 2013, 117, 2032-2040.

119. Alexandrov, V.; Rosso, K.M. Insights into the mechanism of Fe(II) adsorption and oxidation at Fe-clay mineral surfaces from first-principles calculations. J. Phys. Chem. C 2013, 117, 22880-22886.

120. Wander, M.C.F.; Rosso, K.M.; Schoonen, M.A.A. Structure and charge hopping dynamics in green rust. J. Phys. Chem. C 2007, 111, 11414-11423.

121. Qiang, L.H.; Li, Z.F.; Zhao, T.Q.; Zhong, S.L.; Wang, H.Y.; Cui, X.J. Atomic-scale interactions of the interface between chitosan and $\mathrm{Fe}_{3} \mathrm{O}_{4}$. Colloids Surf. A 2013, 419, 125-132.

122. Aryanpour, M.; van Duin, A.C.T.; Kubicki, J.D. Development of a reactive force field for iron-oxyhydroxide systems. J. Phys. Chem. A 2010, 114, 6298-6307.

123. Dismukes, G.C. The metal centers of the photosynthetic oxygen-evolving complex. Photochem. Photobiol. 1986, 43, 99-115.

124. Burns, R.G.; Burns, V.M. Mineralogy. In Marine Manganese Deposits; Glasby, G.P., Ed.; Elsevier: Amsterdam, The Netherlands, 1977; pp. 185-248.

125. O'Reilly, S.E.; Hochella, M.F. Lead sorption efficiencies of natural and synthetic Mn and Fe-oxides. Geochim. Cosmochim. Acta 2003, 67, 4471-4487.

126. Sposito, G. The Chemistry of Soils, 2nd ed.; Oxford University Press: Oxford, UK, 2008.

127. Sparks, D.L. Environmental Soil Chemistry, 2nd ed.; Academic Press: San Diego, CA, USA, 2003.

128. Villalobos, M.; Lanson, B.; Manceau, A.; Toner, B.; Sposito, G. Structural model for the biogenic Mn oxide produced by pseudomonas putida. Am. Mineral. 2006, 91, 489-502.

129. Essington, M.E. Soil and Water Chemistry: An. Integrative Approach; CRC Press: Boca Raton, FL, USA, 2003.

130. Post, J.E. Manganese oxide minerals: Crystal structures and economic and environmental significance. Proc. Natl. Acad. Sci. USA 1999, 96, 3447-3454.

131. Gasparatos, D. Sequestration of heavy metals from soil with Fe-Mn concretions and nodules. Environ. Chem. Lett. 2013, 11, 1-9.

132. Cygan, R.T.; Post, J.E.; Heaney, P.J.; Kubicki, J.D. Molecular models of birnessite and related hydrated layered minerals. Am. Mineral. 2012, 97, 1505-1514. 
133. Kwon, K.D.; Refson, K.; Sposito, G. Surface complexation of Pb(II) by hexagonal birnessite nanoparticles. Geochim. Cosmochim. Acta 2010, 74, 6731-6740.

134. Kwon, K.D.; Refson, K.; Sposito, G. On the role of Mn(IV) vacancies in the photoreductive dissolution of hexagonal birnessite. Geochim. Cosmochim. Acta 2009, 73, 4142-4150.

135. Kwon, K.D.; Refson, K.; Sposito, G. Understanding the trends in transition metal sorption by vacancy sites in birnessite. Geochim. Cosmochim. Acta 2013, 101, 222-232.

136. Pena, J.; Kwon, K.D.; Refson, K.; Bargar, J.R.; Sposito, G. Mechanisms of nickel sorption by a bacteriogenic birnessite. Geochim. Cosmochim. Acta 2010, 74, 3076-3089.

137. Kwon, K.D.; Refson, K.; Sposito, G. Zinc surface complexes on birnessite: A density functional theory study. Geochim. Cosmochim. Acta 2009, 73, 1273-1284.

138. Tebo, B.M.; Bargar, J.R.; Clement, B.G.; Dick, G.J.; Murray, K.J.; Parker, D.; Verity, R.; Webb, S.M. Biogenic manganese oxides: Properties and mechanisms of formation. Annu. Rev. Earth Planet. Sci. 2004, 32, 287-328.

139. Madison, A.S.; Tebo, B.M.; Mucci, A.; Sundby, B.; Luther, G.W. Abundant porewater Mn(III) is a major component of the sedimentary redox system. Science 2013, 341, 875-878.

140. Laha, S.; Luthy, R.G. Oxidation of aniline and other primary aromatic-amines by manganese-dioxide. Environ. Sci. Technol. 1990, 24, 363-373.

141. Stone, A.T. Reductive dissolution of manganese(III/IV) oxides by substituted phenols. Environ. Sci. Technol. 1987, 21, 979-988.

142. Ulrich, H.J.; Stone, A.T. Oxidation of chlorophenols adsorbed to manganese oxide surfaces. Environ. Sci. Technol. 1989, 23, 421-428.

143. Zhang, H.C.; Huang, C.H. Oxidative transformation of triclosan and chlorophene by manganese oxides. Environ. Sci. Technol. 2003, 37, 2421-2430.

144. Zhang, H.C.; Huang, C.H. Reactivity and transformation of antibacterial N-oxides in the presence of manganese oxide. Environ. Sci. Technol. 2005, 39, 593-601.

145. Zhang, H.C.; Huang, C.H. Oxidative transformation of fluoroquinolone antibacterial agents and structurally related amines by manganese oxide. Environ. Sci. Technol. 2005, 39, 4474-4483.

146. Klausen, J.; Haderlein, S.B.; Schwarzenbach, R.P. Oxidation of substituted anilines by aqueous $\mathrm{MnO}_{2}$ : Effect of co-solutes on initial and quasi-steady-state kinetics. Environ. Sci. Technol. 1997, $31,2642-2649$.

147. Banerjee, D.; Nesbitt, H.W. XPS study of dissolution of birnessite by humate with constraints on reaction mechanism. Geochim. Cosmochim. Acta 2001, 65, 1703-1714.

148. Banerjee, D.; Nesbitt, H.W. XPS study of reductive dissolution of birnessite by oxalate: Rates and mechanistic aspects of dissolution and redox processes. Geochim. Cosmochim. Acta 1999, 63, 3025-3038.

149. Durand, J.P.; Senanayake, S.D.; Suib, S.L.; Mullins, D.R. Reaction of formic acid over amorphous manganese oxide catalytic systems: An in situ study. J. Phys. Chem. C 2010, 114, 20000-20006.

150. Reiller, P.E. Modelling metal-humic substances-surface systems: Reasons for success, failure and possible routes for peace of mind. Miner. Mag. 2012, 76, 2643-2658.

151. Wang, N.-H.; Lo, S.-L. Preparation, characterization and adsorption performance of cetyltrimethylammonium modified birnessite. Appl. Surf. Sci. 2014, 299, 123-130. 
152. Myeongjin, K.; Myeongyeol, Y.; Youngjae, Y.; Jooheon, K. Capacitance behavior of composites for supercapacitor applications prepared with different durations of graphene/nanoneedle $\mathrm{MnO}_{2}$ reduction. Microelectron. Reliab. 2014, 54, 587-594.

153. Ahmed, K.A.M.; Huang, K. Synthesis, characterization and catalytic activity of birnessite type potassium manganese oxide nanotubes and nanorods. Mater. Chem. Phys. 2012, 133, 605-610.

154. Xia, H.; Wang, Y.; Lin, J.; Lu, L. Hydrothermal synthesis of $\mathrm{MnO}_{2} / \mathrm{CNT}$ nanocomposite with a CNT core/porous $\mathrm{MnO}_{2}$ sheath hierarchy architecture for supercapacitors. Nanoscale Res. Lett. 2012, 7, 1-10.

155. Jaramillo-Botero, A.; Nielsen, R.; Abrol, R.; Su, J.; Pascal, T.; Mueller, J.; Goddard, W.A. First-principles-based multiscale, multiparadigm molecular mechanics and dynamics methods for describing complex chemical processes. In Multiscale Molecular Methods in Applied Chemistry; Kirchner, B., Vrabec, J., Eds.; Springer-Verlag: Berlin, Germany, 2012; Volume 307, pp. 1-42.

156. Abrams, C.; Bussi, G. Enhanced sampling in molecular dynamics using metadynamics, replica-exchange, and temperature-acceleration. Entropy 2014, 16, 163-199.

157. Stamatakis, M.; Vlachos, D.G. Unraveling the complexity of catalytic reactions via kinetic Monte Carlo simulation: Current status and frontiers. ACS Catal. 2012, 2, 2648-2663.

158. Liu, S.Y.; Kleber, M.; Takahashi, L.K.; Nico, P.; Keiluweit, M.; Ahmed, M. Synchrotron-based mass spectrometry to investigate the molecular properties of mineral-organic associations. Anal. Chem. 2013, 85, 6100-6106.

159. Smalley, M. Clay Swelling and Colloid Stability; Taylor and Francis Group: Boca Raton, FL, USA, 2006.

(C) 2014 by the authors; licensee MDPI, Basel, Switzerland. This article is an open access article distributed under the terms and conditions of the Creative Commons Attribution license (http://creativecommons.org/licenses/by/3.0/). 